formação nodular de $1,5 \times 1,0 \times 1,0 \mathrm{~cm}$, em pólo caudal do pâncreas, com consistência firme, aspecto lobulado e superficie de corte esbranquiçada com áreas acastanhadas. Fragmento do pâncreas com o nódulo foi colhido, fixado em formol e encaminhado para processamento segundo técnica padrão para exame histopatológico e corado por hematoxilina e cosina. Cortes histopatológicos do pâncreas foram submetidos a reação de imuno-histoquímica utilizando sistema LSAB plus da Dako, para caracterização dos possíveis hormônios produzidos pelas células neoplásicas. Microscopicamente, a formação se caracterizava por ser encapsulada, multilobulada composta por células neoplásicas poliédricas ou arredondadas, com núcleos centrais ou excêntricos, que apresentam cromatina frouxa, citoplasma ligeiramente eosinofilico e com granulaçào fina. Estas células se arranjam em pequenos agrupamentos sólidos separados por septos de tecido conjuntivo vascularizado e delicado. A cápsula é fibrosa e exibe células com pigmentos acastanhados grosseiros. O exame imuno-histoquímico caracterizou este tumor como tumor endócrino com produção de insulina, gastrina e somatostatina. As alterações clínicas observadas neste caso são semelhantes as relatadas na literatura nos casos de hipoglicemia. Nos cães idosos as causas mais comuns de hipoglicemia são insuficiência hepática, neoplasia de células $B$ pancreáticas, neoplasia extrapancreática, hipoadrenocorticismo e sepsis. A hipoglicemia nos casos de hipoadrenocorticismo e insuficiência hepática costumam ser brandas e acompanhadas de hiponatremia, hipercalemia, elevação da enzimas hepáticas e hipoproteinemia. No presente caso, a grave hipoglicemia não responsiva à terapia, os valores de sódio e potássio normais e ausência de outras alterações clínicas sugestivas de insuficiência hepática ou sepsis, levaram ao diagnóstico clínico de neoplasia de células $B$. O anatomopatológico confirmou a suspeita clínica e ainda caracterizou a neoplasia como multihormonal. Considera-se que as células neoplásicas produzam e secretam os demais hormônios, porém o aumento da insulina mascara os efeitos dos demais hormônios. Concluise, com a associação clínico anatomopatológica tratar-se de um tumor endócrino multihormonal, sendo a insulina o hormônio relacionado com a síndrome clínica relatada.

\title{
94 - Leucemia monocítica em cão. Relato de caso
}

Bonello, F.L.' ; Ciarlini, P.C.' ; Feitosa, M.M. '; Machado, G.F.'; Silva, I.C.'
1- Curso de Medicina Veterinária da Faculdade de Medicina Veterinária e Agrárias da Universidade Estadual Paulista, Campus de Araçatuba, Araçatuba-SP

As proliferaçòes neoplásicas envolvendo monócitos ou seus precursores são raras, porém foram reportadas em algumas espécies animais. Normalmente apresentam-se como doença aguda num paciente comprometido com severas citopenias, quase que invariavelmente levando o animal a óbito. As leucemias monocíticas podem ser classificadas em dois subtipos - M5a e M5b, dependendo da maturidade das células da linhagem monocítica. O objetivo deste trabalho é relatar um caso de leucemia monocítica aguda num cào que veio a óbito uma semana após o diagnóstico, e acrescentar novas informações ao conjunto daquelas disponíveis na literatura. Um cào macho, de sete anos, da raça Pastor Alemão foi atendido no Hospital Veterinário Luiz Quintiliano de Oliveira - Unesp - Câmpus de Araçatuba, com episódios de vômito e diarréia líqüida amarelada. Apresentava descamaçào micácea generalizada e secreções nasal e ocular purulentas, além de onicogrifose e mucosas hipocoradas. Dos exames complementares, os achados radiográficos revelaram pneumonia e cardiomegalia, enquanto que o hemograma evidenciou anemia normocítica normocrômica sem sinais de resposta medular, eritrócitos em "rouleaux" e raros esquizócitos, além de elevada leucocitose $(362.000 / \mathrm{mL})$. Cerca de $80 \%$ dos leucócitos apresentavam características monocitóides, com intensa vacuolização citoplasmática. Nucléolos aberrantes e figuras de mitose foram achados freqüentes. Os poucos neutrófilos presentes apresentavam hipersegmentaçào. A análise do esfregaço da medula óssea revelou predominância de células monocitóides com características semelhantes às observadas no sangue periférico, além de raras células eritróides e ausência de megacariócitos. Os achados macroscópicos de necropsia evidenciaram aumento de volume do baço e linfonodos, bem como nódulos esbranquiçados 
infiltrando o miocárdio dos ventrículos direito e esquerdo. No exame histopatológico pôdese constatar infiltrados de células mononucleares monocitóides em diversos órgãos, bem como escassez de eritrócitos nos vasos sangǘneos. Os achados do hemograma, do exame de medula óssea, em conjunto com aqueles da necropsia e do histopatológico, permitiram concluir o diagnóstico de leucemia monocítica aguda.

Hette K.'; Rahal S.C.'

Lopes, F.M. '; Leon Roman, M.A.'; Ferro, D.G. ${ }^{2}$; Correa, H.L. ${ }^{2}$; Venturini, M.A.F.A. ${ }^{3}$; Gioso, M.A. ${ }^{4}$

\section{5 - Defeitos congênitos do palato em cães. Relato de três casos}

1- Faculdade de Medicina Veterinária e Zootecnia da Universidade Estadual Paulista, Campus de Botucatu, Botucatu-SP

Os defeitos congênitos do palato são pouco freqüentes em càes, sendo os braquicefálicos os mais predispostos. Uma fenda palatina primária consiste em qualquer fenda cranial ao forame incisivo e envolvendo o lábio, ao passo que a fenda secundária ocorre caudal ao forame incisivo. $\mathrm{O}$ objetivo do trabalho é relatar três casos de cães com fendas palatinas congênitas, que foram encaminhados ao hospital veterinário da Unesp, Campus de Botucatu. Caso 1 - cadela da raça Bulldog, dois meses de idade, apresentando lábio fendido e fenda na linha média dos palatos duro e mole. Caso 2 - cadela da raça Fox Terrier, dois meses de idade, com fenda unilateral do palato mole. Caso 3 - cão da raça Poodle, macho, quatro meses e três semanas de idade, com fenda na linha média dos palatos duro e mole. $\mathrm{O}$ método de tratamento empregado nos casos 1 e 3 foi à técnica de retalho duplo com reposição medial e incisòes de alívio de tensão. Este foi de fácil execução e apresentou bons resultados em ambos os animais. No caso 3, utilizou-se o método de sutura em duas camadas, que se mostrou inadequado. As fendas palatinas, especialmente as do palato duro e mole, são deformidades que exigem correção cirúrgica por acarretarem risco de vida. A identificação precoce da precoce favorece a instituição de medidas terapêuticas e de suporte nutricional. Por causa da possibilidade de envolvimento hereditário, preconiza-se a não utilização do animal para fins reprodutivos.

\section{6 - Fraturas mandibulares em cães. Estudo retrospectivo}

1- Laboratório de Odontologia Comparada da Faculdade de Medicina Veterinária e Zootecnia da Universidade de São Paulo, São Paulo-SP

2- Pós-graduação da Faculdade de Medicina Veterinária e Zootecnia da Universidade de São Paulo, Såo Paulo-SP

3- Médica Veterinária Autônoma

4- Departamento de Cirurgia da Faculdade de Medicina Veterinária e Zootecnia da Universidade de São Paulo, São Paulo-SP

As fraturas mandibulares são consideradas afecções pouco freqüentes em cães, decorrentes, na maior parte dos casos, a traumatismos. As fraturas patológicas, decorrentes principalmente a periodontites e neoplasias, ocorrem com maior freqüência em cães idosos e de pequeno porte, especialmente após brigas ou iatrogenicamente, durante a exodontia. Existem poucos estudos sobre a prevalência de fraturas mandibulares nesta espécie, especialmente quanto a: etiologia, distribuição etária e localização da fratura; não havendo trabalhos semelhantes no Brasil. Estes fatores são considerados fundamentais para a determinação do tipo e padrão da lesão, do prognóstico e do método de tratamento da fratura. Assim, o estabelecimento desses fatores e o conhecimento de suas características e prevalências são de grande valia para a rotina clínica e cirúrgica do profissional médico veterinário. As fichas clínicas de 3666 animais da espécie canina atendidos entre agosto de 1994 e abril de 2003 no ODONTOVET 